\title{
THE EFFECT OF CALCIUM ON ACETYLCHOLINE RECEPTOR SYNTHESIS ${ }^{1}$
}

\author{
JAMES L. MCMANAMAN," JAMES C. BLOSSER, AND STANLEY H. APPEL
}

The Jerry Leais Neuromuscular Disease Research Center. Department of Neurology, Baylor College of Medicine, Houston. Texas 77030

\begin{abstract}
The level of cytoplasmic calcium has been proposed to act as a regulator of acetylcholine receptor synthesis (Betz, II., and J. P. Changeaux (1979) Nature 278: 749-751). However, there is little known about the effect of altered calcium levels on the metabolism of the acetylcholine receptor. We have investigated the effect of decreased extracellular calcium on the metabolism of acetylcholine receptors in cultured rat myotubes. Our results show that the acetylcholine receptor levels on the surface of myotubes were decreased 25 to $30 \%$ following overnight incubation in calcium-deficient medium. In contrast, creatine phosphokinase activity levels and total protein synthesis were unaffected. Calcium depletion did not change the rate of receptor degradation significantly $(0.037$ hr ', compared to $0.033 \mathrm{hr}^{-1}$ for control cells) but dramatically decreased the rate of incorporation of new acetylcholine receptors into the plasma membrane. The time course for incorporation of new acetylcholine receptors into the plasma membrane of calcium-depleted cells was similar to control cells treated with cycloheximide, suggesting that de novo receptor synthesis was inhibited. These results indicate that intracellular calcium levels and acetylcholine receptor synthesis are not related in a simple reciprocal fashion and suggest that the regulation of acetylcholine receptor levels involves more than one intracellular compartment of calcium.
\end{abstract}

Muscle activity has been shown to influence the acetylcholine (Ach) receptor levels of skeletal muscle in tissue culture as well as in vivo (Lomo and Rosenthal, 1972; Shainberg and Burstein, 1976). Since it is well known that contractile activity involves fluctuations in myoplasmic calcium levels, changes in the level of myoplasmic calcium were hypothesized to be responsible for the activity-related changes in Ach receptor synthesis (Betz and Changeaux, 1979). Accordingly, increased Ach receptor levels would be associated with decreased levels of Inyoplasmic calcium, and decreased Ach receptor levels would be associated with increased myoplasmic calcium. Our studies demonstrate that changes in extracellular calcium influence the synthesis of Ach receptors and suggest that the relationship between intracellular calcium and Ach receptor levels may be more complex than previously hypothesized.

\section{Materials and Methods}

Materials. Dulbecco's Modified Eagle's Medium (DMEM) and -Ca Modified Eagle's Medium were pur-

\footnotetext{
'We would like to thank Dr. Michael Merickel for performing the electrophysiological measurements. This research was supported in part by a Muscular Dystrophy Association Jerry Lewis Neuromuscular Disease Center grant and National Institutes of Health Grant NS 14380.

"To whom correspondence should be addressed.
}

chased from Grand Island Biological Co., Grand Island, NY. Horse serum was purchased from Irvine Scientific, Santa Ana, CA. $\alpha$-Bungarotoxin was purchased from Miami Serpentarium. $\left[{ }^{35} \mathrm{~S}\right]$ Methionine $(800 \mathrm{Ci} / \mathrm{mmol})$ was purchased from New England Nuclear, Boston, MA. Calf thymus DNA was purchased from Sigma Chemical Co., St. Louis, MO. All other chemicals were reagent grade quality.

Culture conditions. Primary muscle cultures were prepared by trypsinization of the hindlimb muscles from newborn rats as described previously (Appel et al., 1977). The cultures were plated at $2 \times 10^{6}$ cells per $35-\mathrm{mm}$ culture dish in Dulbecco's Modified Fagle's Medium supplemented with $10 \%$ horse serum, $0.5 \%$ chicken embryo extract. The immature myoblasts ceased dividing and began to fuse, forming multinucleated myotubes, approximately $72 \mathrm{hr}$ after plating. Fusion was essentially complete by the 5 th day after plating as determined by the number of multinucleated muscle fibers per dish. Cultures were fed with fresh media on the 3rd and 5th day after plating. Some experiments (e.g., the measurement of $\left[^{35} \mathrm{~S}\right\rceil$ methionine incorporation into protein and the determination of the DNA content or creatine phosphokinase (CPK) activity levels) required the elimination of fibroblasts which are normal contaminants of muscle cultures. This was accomplished by feeding cultures with fresh media containing $10^{-5} \mathrm{M}$ cytosine arabinoside on the 3rd and 5th day after plating. Cytosine arabinoside 
treatment was found not to affect either Ach receptor degradation or Ach receptor levels. After 7 days in culture, the media were changed to a calcium-deficient medium containing $0.2 \mathrm{~mm}$ calcium (-Ca Modified Eagle's Medium, $10 \%$ horse serum, $0.5 \%$ chick embryo extract) or to control medium containing $2.0 \mathrm{~mm}$ calcium (Modified Eagle's Medium, 10\% horse serum, 0.5\% chick embryo extract). Media containing calcium concentrations between 0.2 and $2.0 \mathrm{~mm}$ were prepared by adding $\mathrm{CaCl}_{2}$ to calcium-deficient medium. Calcium concentrations were determined by atomic absorption spectroscopy.

Preparation of ${ }^{125} I-\alpha$-bungarotoxin $\left({ }^{125} I-\alpha-B g t x\right) . \alpha-$ Bungarotoxin ( $\alpha-\mathrm{Btx})$ was iodinated by the procedure of Mickey et al. (1971). Monoiodinated toxin was separated from ${ }^{125}$ I and di-iodinated toxin by chromatography on CM-52 cellulose (Lukasiewicz et al., 1978). The concentration of ${ }^{125} \mathrm{I}-\alpha$-bungarotoxin was determined by a competition assay utilizing a quantity of ${ }^{125} \mathrm{I}-\alpha$-bungarotoxin which saturated purified receptor (from Torpedo californica). The concentration was calculated by measuring the amount of unlabeled toxin required to inhibit ${ }^{125} \mathrm{I}$ toxin binding by $50 \%$. The specific activity of the monoiodinated $\alpha$-bungarotoxin varied between 10 and 47 $\mathrm{cpm} /$ fmol.

Measurement of acetylcholine receptors. Ach receptor levels on the surface of the myotubes were measured using ${ }^{125} \mathrm{I}-\alpha$-bungarotoxin as described previously (Blosser and Appel, 1979).

Receptor degradation. The rate of Ach receptor degradation was measured as described previously (Blosser and Appel, 1979).

Receptor incorporation. The insertion of new Ach receptors into myotube membranes was measured by the technique of Devreotes and Fambrough (1975). Ach receptors on the surface of the myotubes were blocked with $60 \mathrm{nM} \alpha$-Btx. The excess $\alpha$-bungarotoxin was removed by washing the cultures three times with Hanks' balanced salt solution (HBSS). The myotubes then were incubated for 13 to $18 \mathrm{hr}$ in test media. The number of new Ach receptors that accumulated on the surface of the myotubes was measured using ${ }^{125} \mathrm{I}-\alpha$-Btx.

Intracellular acetylcholine receptors. The number of intracellular Ach receptors was measured by the technique of Devreotes and Fambrough (1975). Surface Ach receptors were blocked with $60 \mathrm{~nm} \alpha$-Btx, excess toxin was removed by aspiration, and the plates were washed three times with $2 \mathrm{ml}$ of HBSS. The cells then were extracted with $50 \mathrm{~mm}$ Tris (tris(hydroxymethyl)aminomethane), $50 \mathrm{~mm} \mathrm{NaCl}, 1 \%$ Triton X-100, pH 7.4. Then, the extract was incubated for $1 \mathrm{hr}$ with $20 \mathrm{nM}{ }^{125} \mathrm{I}-\alpha$-Bgtx. ${ }^{12: 5} \mathrm{I}-\alpha$-Bgtx bound to Ach receptor was separated from unbound ${ }^{125} \mathrm{I}-\alpha$-Bgtx on a 5 to $20 \%$ sucrose gradient in 50 m $\mathrm{m}$ Tris, $50 \mathrm{~mm} \mathrm{NaCl}, 1 \%$ Triton X-100. The number of intracellular Ach receptors was calculated from the peak of radioactivity at $9 \mathrm{~S}$.

Creatine phosphokinase activity. The creatine phosphokinase activity of the myotubes was measured according to Shainberg et al. (1971).

Measurement of DNA content. The DNA content of cells incubated in control or calcium-deficient medium was assayed by the method of Hinegardner (1971). Cul- tures to be assayed for DNA content were treated with $10^{-5}$ M cytosine arabinoside, as described under "Culture conditions," to eliminate fibroblasts. After incubating in control or calcium-deficient medium for $15 \mathrm{hr}$, the medium was removed and the cultures were frozen at $-80^{\circ} \mathrm{C}$. Individual cultures then were scraped into $1.0 \mathrm{ml}$ of $10 \%$ trichloroacetic acid, transferred to siliconized 10 $\times 75 \mathrm{~mm}$ test tubes and centrifuged at $3000 \mathrm{rpm}$ for 10 min in a clinical centifuge. The precipitate was washed twice with absolute ethanol and dried at $50^{\circ} \mathrm{C}$. The dried precipitates then received $0.10 \mathrm{ml}$ of diaminobenzoic acid $(0.4 \mathrm{gm} / \mathrm{ml}$ of double distilled water $)$ and were heated at $60^{\circ} \mathrm{C}$ for $45 \mathrm{~min}$. Next, each tube received $1.5 \mathrm{ml}$ of ultrapure $\mathrm{HCl}$. Fluorescence measurements were made by exciting at $420 \mathrm{~nm}$ and recording at $510 \mathrm{~nm}$, using an Aminco SPF-500 spectrofluorometer. Calf thymus DNA was used as a standard.

Measurement of protein synthesis. Protein synthesis was measured in a minimal control and calcium-deficient media prepared by diluting Dulbecco's Modified Eagle's Medium 1:10 into $\mathrm{Ca}^{2+}$ - and $\mathrm{Mg}^{2+}$-free HBSS; control medium was prepared by replenishing the $\mathrm{Mg}^{2+}$ and $\mathrm{Ca}^{2+}$ to the concentration in normal DMEM. Calcium-deficient medium was prepared by replenishing only $\mathrm{Mg}^{2+}$. The total concentration of calcium in both media was determined by atomic absorption spectroscopy. The Ach receptor levels of myotubes incubated 13 to $18 \mathrm{hr}$ in minimal control medium were identical to the Ach receptor levels of myotubes incubated in normal DMEM.

The effect of incubating cells in calcium-deficient medium on the general protein synthesis was measured by incubating cells in minimal control or calcium-deficient medium for $15 \mathrm{hr}$. At this time, $14 \mu \mathrm{Ci}$ of [ $\left.{ }^{35} \mathrm{~S}\right]$ methionine were added to each culture dish. The cultures then were incubated for an additional $5 \mathrm{hr}$ at $37^{\circ} \mathrm{C}\left(5 \% \mathrm{CO}_{2}\right)$ and washed free of excess of $\left[{ }^{35} \mathrm{~S}\right]$ methionine; the incorporation of $\left[{ }^{35} \mathrm{~S}\right]$ methionine into protein was measured as described previously (Blosser and Appel, 1979).

Measurement of electrical properties. Electrical properties of cells were measured after the cells were incubated for $15 \mathrm{hr}$ in calcium-deficient or control medium. Measurements were made, at $22^{\circ} \mathrm{C}$, in the respective incubation medium using standard intracellular electrophysiological techniques (Merickel et al., 1981). Action potentials were clicited, from cells that did not fire spontaneously, out of anode break.

\section{Results}

The Ach receptor levels on the surface of myotubes were decreased relative to control cultures by incubating myotubes in calcium-deficient medium. The extent of the decrease varied between 25 and $30 \%$ over a $13-$ to 15 $\mathrm{hr}$ period. If the cultures incubated in calcium-deficient medium were refed with control medium and incubated for an additional $24 \mathrm{hr}$, the Ach receptor levels returned to control values (Fig. 1).

In contrast, the CPK activity levels associated with the myotubes decreased only 8 to $10 \%$ after overnight incubation in calcium-deficient medium (Table I). This result agrees with the earlier observation that, unlike the developmental appearance of CPK activity, the CPK activity of mature myotubes is unaffected by the concen- 


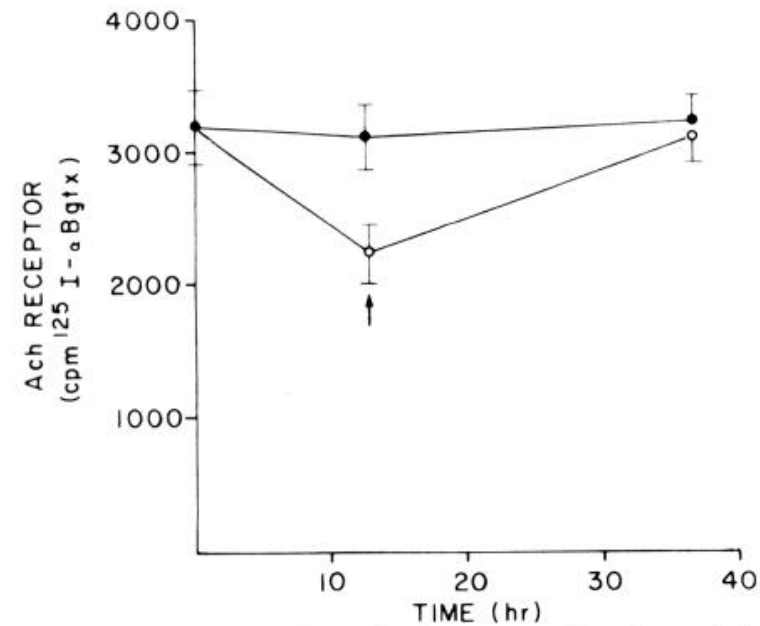

Figure 1. The effect of incubating myotubes in calciumdeficient medium on the level of surface Ach receptors. Myotubes were incubated with either control medium or calciumdeficient medium for $13 \mathrm{hr}$. Some of the cultures incubated in calcium-deficient or control medium then were refed with control medium (arrow) and incubated for an additional $24 \mathrm{hr}$. The Ach receptor levels on the surface of the myotubes were determined at the indicated times. Control medium; $\bigcirc$, calciumdeficient medium. Results are expressed as the average \pm SD of three cultures. Specific activity of ${ }^{125} \mathrm{I}-\alpha-\mathrm{Bgtx}=24 \mathrm{cpm} / \mathrm{fmol}$.

TABLE I

The effect of culturing myotubes in calcium-deficient medium on cellular viability and metabolism

The Ach receptor levels and the CPK activity levels associated with myotubes treated with $10^{-5} \mathrm{M}$ cytosine arabinoside were measured after incubation in calcium-deficient or control medium for $15 \mathrm{hr}$. Incorporation of $\left[{ }^{[5} \mathrm{S}\right.$ |methionine into the total cellular protein of cytosine arabinoside-treated myotubes was measured during a 5-hr pulse following incubation in calcium-deficient or control medium for $15 \mathrm{hr}$. Resting membrane potential (RMP) and afterhyperpolarization were measured in their respective incubation media after incubating the cells for $15 \mathrm{hr}$ in control or calcium-deficient medium. With the exception of RMP and afterhyperpolarization, all results are expressed as the average \pm SD of three cultures. The results for RMP and afterhyperpolarization are expressed as the average $\pm \mathrm{SD}$ of at least six muscle fibers per culture plate.

\begin{tabular}{lcc}
\hline & \multicolumn{2}{c}{ Medium } \\
\cline { 2 - 3 } & Control $\pm \mathrm{SD}$ & $\begin{array}{c}\text { Calcium-deficient } \\
\pm \mathrm{SD}\end{array}$ \\
\hline $\begin{array}{l}\text { Ach receptor level }\left(\mathrm{cpm}^{125} \mathrm{I}-\alpha-\right. \\
\quad \text { Bgtx/plate) }\end{array}$ & $1,180 \pm 86$ & $880 \pm 70$ \\
CPK activity (IU/plate) & $0.053 \pm 0.002$ & $0.050 \pm 0.001$ \\
${ }^{35}$ incorporation (cpm/plate) & $19,153 \pm 5,537$ & $22,934 \pm 1,417$ \\
DNA ( $\mu$ g/plate) & $5.2 \pm 0.48$ & $5.4 \pm 0.23$ \\
RMP (mV) & $45.8 \pm 1.93$ & $48.6 \pm 1.56$ \\
Afterhyperpolarization $(\mathrm{mV})$ & $16.2 \pm 1.5$ & $3.6 \pm 3.2$ \\
\hline
\end{tabular}

tration of calcium in the culture medium (Shainberg et al., 1971).

It is unlikely that the decreased levels of Ach receptor are due to degeneration of muscle fibers (Ozawa, 1978) since Ach receptor levels were increased to control levels by the addition of control medium and the CPK activity levels were unaffected by culturing cells in calcium-deficient medium. In addition, we found that the DNA content of myotubes incubated in calcium-deficient medium was identical to control cells (Table I) and the incorporation of $\left[{ }^{35} \mathrm{~S}\right]$ methionine into protein, in myotubes preincubated in calcium-deficient medium for 15 $\mathrm{hr}$ and then pulsed with $\left[{ }^{35} \mathrm{~S}\right]$ methionine for an additional $5 \mathrm{hr}$, was identical to control cultures. Thus, incubation of myotubes in calcium-deficient medium did not interfere with general protein synthesis (Table I). However, as an additional test of the integrity of these myotubes, we measured their resting membrane potential and tested their ability to fire action potentials when stimulated by a depolarizing impulse. The resting membrane potentials were found to be identical to control cells (Table I), and interestingly, although cells incubated in calcium-deficient medium were capable of firing action potentials, their action potentials exhibited a decreased afterhyperpolarization (Fig. 2). The afterhyperpolarization has been shown to be an outward going $\mathrm{K}^{+}$current that is activated by increased intracellular calcium (Meech, 1976). This result suggests that the intracellular calcium levels may be altered in myotubes incubated in calcium-deficient medium.

The decreased levels of surface Ach receptors could be the result of either an increased rate of receptor degradation or a decreased rate of insertion of new Ach receptors into the plasma membrane. We found that Ach receptor degradation, as measured by the loss of ${ }^{125} \mathrm{I}-\alpha$ bungarotoxin from the myotube surface, was relatively unaffected by incubating myotubes in calcium-deficient medium (Fig. 3). However, the insertion of new Ach receptors into the plasma membrane was profoundly decreased relative to control. The influence of the concentration of calcium in the culture medium on the insertion of Ach receptors into plasma membranes is shown in Figure 4.

The sequence of events leading to the incorporation of newly synthesized Ach receptors into the plasma membrane of cultured myotubes has been shown to involve the formation of an intracellular pool of Ach receptors from which Ach receptors are transported to the surface of the myotubes (Devreotes and Fambrough, 1975, 1976). Thus, a decreased rate of incorporation could be due to either decreased incorporation of newly synthesized Ach receptors into the intracellular pool, decreased transport of Ach receptors from the pool to the surface of the

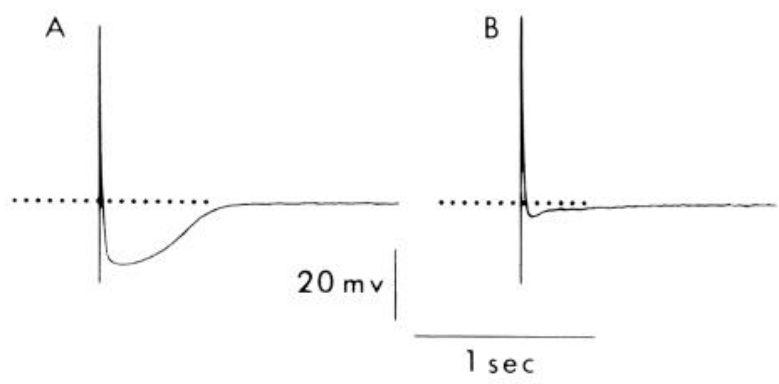

Figure 2. The effect of incubating myotubes in calciumdeficient medium on action potentials. Cultures were incubated for $15 \mathrm{hr}$ in control or calcium-deficient medium prior to making electrophysiological measurements. Action potentials were elicited from anode break. Dotted line identifies resting membrane potential. $A$, Control; $B$, calcium deficient. 
myotubes, or both. Therefore, the effect of calcium-deficient medium on the level of intracellular Ach receptors, as well as on the transport of Ach receptors from the intracellular pool to the myotube surface, was measured.

The incorporation rate of Ach receptors into the plasma membrane is not affected immediately by incubating the cultures in calcium-deficient medium but requires a 4-hr lag period before the incorporation rate is decreased (Fig. 5). A similar time lag period also occurred when control cultures were treated with $3 \mu \mathrm{g} \mathrm{ml}^{-1}$ of cycloheximide to stop protein synthesis.

The lag in the effect of protein synthesis inhibitors on

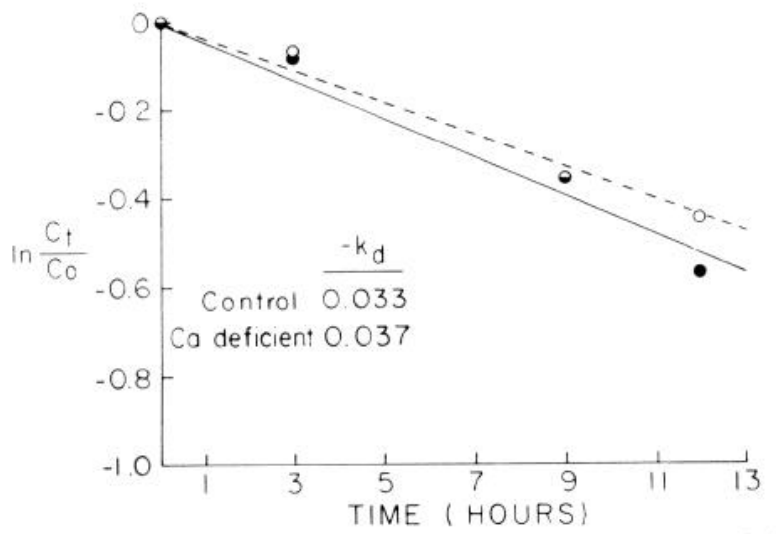

Figure 3. The effect of incubating myotubes in calciumdeficient medium on Ach receptor degradation. The rate of degradation was measured at $37^{\circ} \mathrm{C}$ as described under "Materials and Methods." $\bigcirc$, Control medium; - calcium-deficient medium. The degradation constants were calculated from linear regression analysis of the data. The degradation rate constants are expressed as hours ${ }^{-1}$.

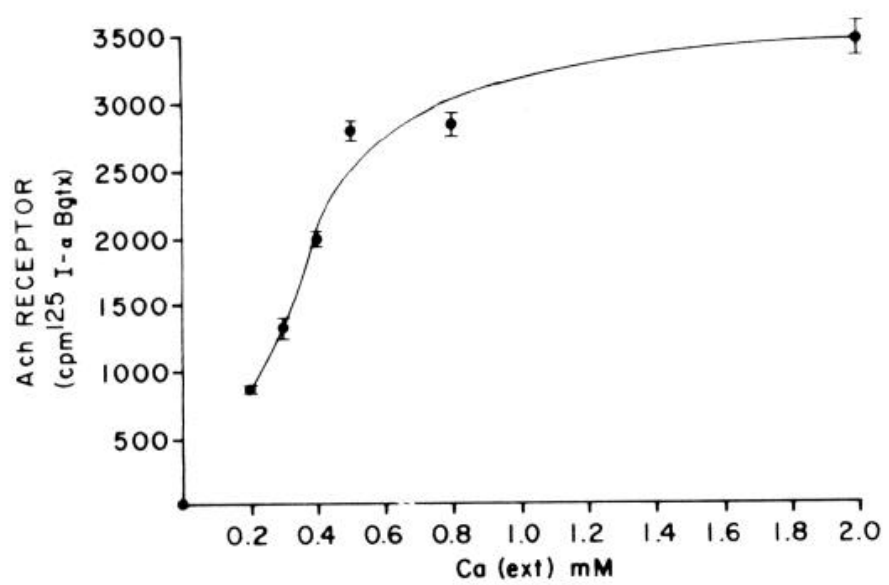

Figure 4. The effect of various extracellular calcium concentrations on the incorporation of new Ach receptors into myotube plasma membranes. Existing Ach receptors on the surface of the myotubes were blocked with unlabeled $\alpha$-bungarotoxin. The cultures then were washed and refed with fresh media containing various concentrations of calcium. The cultures were incubated for $15 \mathrm{hr}$ at $37^{\circ} \mathrm{C}$ in $5 \% \mathrm{CO}_{2}$. The number of Ach receptors incorporated into myotube membranes was measured using ${ }^{125} \mathrm{I}-\alpha$-bungarotoxin. The total calcium concentration in the medium of each culture dish was determined by atomic absorption spectroscopy. The results are expressed as the average $\pm \mathrm{SD}$ of three cultures. Specific activity of ${ }^{125} \mathrm{I}-\alpha-\mathrm{Bgtx}=$ $10 \mathrm{cpm} / \mathrm{fmol}$.

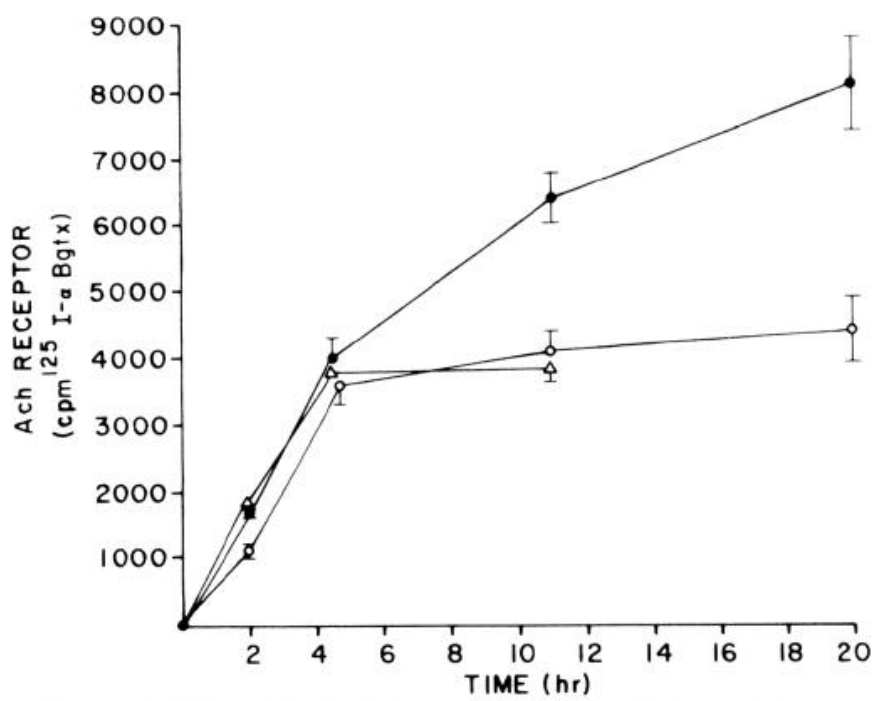

Figure 5. The effect of decreased extracellular calcium on the time course for incorporation of Ach receptor into myotube membranes. The time course of the appearance of Ach receptors on the surface of the myotubes was measured after blocking the existing Ach receptors with unlabeled $\alpha$-bungarotoxin. The cultures were incubated with either control medium (-), calcium-deficient medium (O), or control medium containing $3 \mu \mathrm{g}$ $\mathrm{ml}^{-1}$ of cycloheximide $(\triangle)$. The incorporation of new Ach receptors into myotube plasma membranes was measured at the indicated times using ${ }^{125} \mathrm{I}-\alpha$-bungarotoxin. The concentration of cycloheximide used in these experiments completely blocks the incorporation of $\left[{ }^{35} \mathrm{~S}\right]$ methionine into protein within $1 \mathrm{hr}(\mathrm{J} . \mathrm{L}$. McManaman, J. C. Blosser, and S. H. Appel, unpublished observations). Results are expressed as the average \pm SD of three cultures. Specific activity of ${ }^{125} \mathrm{I}-\alpha$-Bgtx $=47 \mathrm{cpm} / \mathrm{fmol}$.

the incorporation of Ach receptors into myotube membranes has been shown to be due to the transport of presynthesized Ach receptors from an intracellular pool to the surface (Devreotes and Fambrough, 1975, 1976), with the eventual decrease in the rate of insertion being due to the exhaustion of this intracellular pool. The similarity of the time course for Ach receptor incorporation in calcium-deficient medium to the time course for Ach receptor incorporation in the presence of cycloheximide suggests that the rate of transport of receptors from the intracellular pool to the surface is unaffected by the concentration of calcium in the medium. This interpretation is in accord with an earlier report stating that the transport of Ach receptors from the intracellular pool to the surface was unaffected by the calcium concentration in the medium (Fambrough et al., 1974). In contrast, the intracellular pool of Ach receptors was decreased by incubating myotubes in calcium-deficient medium (control, $32 \pm 6 \mathrm{fmol}$; calcium deficient, $17 \pm 3 \mathrm{fmol}$ ). These results suggest that calcium depletion alters some fundamental step in the formation of Ach receptors rather than affecting the mobilization of Ach receptors to the surface.

These results show that the incorporation of newly synthesized Ach receptors into the plasma membrane of cultured myotubes is dependent on the concentration of calcium in the culture medium and suggest that an early step in the synthesis of Ach receptors, possibly de novo synthesis, is a calcium-dependent step. 
The modest decrease in Ach receptor levels (Fig. 1) that accompanied the dramatic inhibition of Ach receptor synthesis (Fig. 5) is consistent with the theoretical decrease based on the results in Figure 5 and the measured rate of Ach receptor degradation (18.6 hr). If it is assumed that Ach receptor synthesis continues at the control rate for $4 \mathrm{hr}$ after changing to calcium-deficient medium (Fig. 5) and then stops, 29\% of the surface receptors will be lost in the subsequent 9 -hr period. This value agrees with the decrease in receptor levels shown in Figure 1.

\section{Discussion}

Our results support the view that the level of intracellular calcium is important in the regulation of Ach receptor synthesis by contractile activity (Betz and Changeaux, 1979). However, this study suggests a relationship between intracellular calcium and Ach receptor levels that is qualitatively different from earlier work. Previously, increased Ach receptor synthesis was thought to be associated with decreased myoplasmic calcium levels. This relationship between myoplasmic calcium levels and Ach receptor synthesis was inferred from experiments involving agents which affect contractile activity. For example, receptor levels were increased by D-600 (Prives, 1976), which blocks the voltage-dependent calcium channel, and by tetrodotoxin (Shainberg and Burstein, 1976; Betz and Changeaux, 1979), which blocks excitation. These agents inhibited contractile activity and presumably decreased the average myoplasmic calcium levels. Conversely, $\Lambda$ ch receptor levels were decreased by electrical stimulation (Shainberg and Burstein, 1976; Reiness and Hall, 1977), veratridine (Betz and Changeaux, 1979), which causes membrane depolarization by increasing sodium permeability, and caffeine (Birnbaum et al., 1980), which stimulates release of calcium from the sarcoplasmic reticulum, all of which presumably increase the average myoplasmic calcium levels.

While we did not measure intracellular calcium levels, it is not unreasonable to assume that prolonged incubation of myotubes in calcium-deficient medium also reduces intracellular calcium. This assumption is supported by the decreased amplitude of the calcium-dependent afterhyperpolarization. Myotubes incubated in calcium. deficient medium for prolonged periods also did not contract spontaneously, although control cells exhibited numerous contractions (J. L. McManaman, J. C. Blosser, and S. H. Appel, unpublished observations). Therefore, our results suggest that decreased levels of intracellular calcium are associated with decreased Ach receptor synthesis as opposed to the anticipated increase in Ach receptor synthesis as predicted by the previous hypothesis (Betz and Changeaux, 1979).

In muscle cells, intracellular calcium is distributed among several membrane-bound pools (e.g., sarcoplasmic reticulum, mitochondria, and nucleus). While there does not appear to be a consistent correlation between Ach receptor levels and myoplasmic calcium levels, there may be a correlation with the calcium levels of other intracellular compartments. Recently, Birnbaum et al. (1980) have suggested that increased Ach receptor levels are correlated with increased levels of calcium in the sarco- plasmic reticulum. They found that agents which might be expected to increase sarcoplasmic reticulum calcium levels (e.g., sodium dantrolene, which blocks release from sarcoplasmic reticulum, and high concentrations of calcium in the culture medium) increase Ach receptor levels, while agents which tend to decrease sarcoplasmic reticulum calcium levels, such as caffeine and electrical stimulation, decrease Ach receptor levels. While this hypothesis would reconcile our results with earlier results, it is difficult to understand $(a)$ how changes in sarcoplasmic reticulum calcium levels would influence protein synthesis and (b) given the normally high concentration of calcium in the sarcoplasmic reticulum, how agents like tetrodotoxin or D-600 could alter the concentrations of sarcoplasmic reticulum calcium significantly. However, it is also conceivable that the calcium levels of other intracellular compartments, such as the nucleus, could be influenced directly by changes in extracellular calcium levels and influenced indirectly by altered contractile activity.

Alternatively, there may be multiple pools of calcium which are important in the regulation of Ach receptor synthesis, and agents which interfere with contractile activity may influence Ach receptor synthesis by a mechanism distinct from that involving extracellular calcium. For example, it has been reported recently that decreased extracellular calcium disaggregates surface Ach receptors on muscle cells in organ cultures (Bloch and Steinbach, 1979). It is conceivable that the synthesis of Ach receptors could be controlled by the state of aggregation of surface Ach receptors. Thus, the effect of decreased extracellular calcium on Ach receptor synthesis could be secondary to its effect on receptor aggregation.

\section{References}

Appel, S. H., R. Anwyl, M. W. McAdams, and S. Elias (1977) Accelerated degradation of acetylcholine receptor from cultured rat myotubes with myasthenia gravis sera and globulins. Proc. Natl. Acad. Sci. U. S. A. 74: 2130-2134.

Betz, H., and J. P. Changeaux (1979) Regulation of muscle acetylcholine receptor synthesis in vitro by cyclic nucleotide derivatives. Nature 278: 749-751.

Birnbaum, M., M. A. Reis, and A. Shainberg (1980) Role of calcium in regulation of Ach receptor synthesis in cultured muscle cells. Pfluegers Arch. 385: 37-43.

Bloch, R. J., and J. H. Steinbach (1979) The effects of $\mathrm{Ca}^{2+}$ deprivation on accumulation of acetylcholine receptor at the developing neuromuscular junction. Soc. Neurosci. Abstr. 5: 476.

Blosser, J. B., and S. H. Appel (1979) Regulation of acetylcholine receptor by cyclic AMP. J. Biol. Chem. 255: 1235-1238.

Devreotes, P. N., and D. M. Fambrough (1975) Acetylcholine receptor turnover in membranes of developing muscle fibers. J. Cell Biol. 65: 335-358.

Devreotes, P. N., and D. M. Fambrough (1976) Turnover of acetylcholine receptors in skeletal muscle. Cold Spring Harbor Symp. Quant. Biol. 40: 237-251.

Fambrough, D. M., H. C. Hartzell, J. E. Rash, and A. K. Ritchie (1974) Receptor properties of developing muscle. Ann. N. Y. Acad. Sci. 228: 47-62.

Hinegardner, R. T. (1971) An improved fluorometric assay for DNA. Anal. Biochem. 39: 197-201.

Lomo, T., and J. Rosenthal (1972) Control of Ach sensitivity by muscle activity in the rat. J. Physiol (Lond.) 221: 493-513.

Lukasiewicz, D. J., M. R. Hanley, and E. L. Bennett (1978) 
Properties of radio-labelled $\alpha$-bungarotoxin derivatives and their interaction with nicotinic acetylcholine receptors. Biochemistry 17: 2308-2313.

Meech, R. W. (1976) Intracellular calcium and the control of membrane permeability. Symp. Soc. Exp. Biol. 30: 161-191.

Merickel, M. B., R. Gray, P. Chauvin, and S. H. Appel (1981) Electrophysiology of human muscle in culture. Exp. Neurol., in press.

Mickey, D. D., P. N. McMillan, S. H. Appel, and E. D. Day (1971) The specificity and cross-reactivity of antisynaptosome antibodies as determined by sequential adsorption analysis. J. Immunol. 107: 1599-1610.

Ozawa, E. (1978) Differences in sensitivity to $\mathrm{Ca}$ ion lack between myoblasts and large myotubes from chicken breast muscle. Dev. Growth Differ. 20: 179-189.
Prives, J. M. (1976) Appearance of specialized cell membrane components during differentiation of embryonic skeletal muscle cells in culture. In Surface Membrane Receptors, R. A. Bradshaw, W. A. Frazier, R. C. Merrel, D. I. Gottlieb, and R. A. Hogue-Angelotti, eds., pp. 363-375, Plenum, New York.

Reiness, C. G. and Z. W. Hall (1977) Electrical stimulation of denervated muscles reduces incorporation of methionine into Ach receptor. Nature 268: 655-657.

Shainberg, A., and M. Burstein (1976) Decrease of acetylcholine receptor synthesis in muscle cultures by electrical stimulation. Nature 264: 368-369.

Shainberg, A., G. Yagil, and D. Yaffe (1971) Alterations of enzymatic activities during muscle differentiation in vitro. Dev. Biol. 25: 1-29. 